\title{
Variables affecting outcome of laparoscopic cholecystectomy in acute cholecystitis
}

\author{
Ahmed M. Abozied, Nabila M. Shams, Yehia H. Zayed, Sahar \\ B.Alfeki,and Sayed A. Mostafa
}

Surgical department Azhar Faculty of Medicine for Girls

\begin{abstract}
The use of laparoscopic cholecystectomy (LC) for treatment of acute cholecystectomy (Ac) and timing of this technique are a subject of debate. This study was undertaken to evaluate our experience with early LC as a safe and effective treatment of these cases.

Charts for all patients who had undergone LC for the diagnosis of AC were done. They were divided into 2 groups based on the length of time from onset of symptoms to surgical intervention, group 1 "early" less than $72 \mathrm{~h}$ (number of patients $(\mathrm{n})=12$ ) and group 2 "delayed" more than $72 \mathrm{~h}(\mathrm{n}=22)$.

Comparing both groups, the conversion rate to an open cholecystectomy (OC) was significantly less in early group than delayed group $(8.3 \%$ \& $41 \%)$ respectively. Furthermore, operative time was (76 minuets versus $93 \mathrm{~m}$ ), postoperative hospital stay was (1.3 versus 3 days) and total hospitalization was (2.2 versus 4.5 days) respectively.

In conclusion LC is safe and effective technique for treatment of AC. Patents treated within $72 \mathrm{~h}$ of onset of symptoms has a lower conversion rate to $\mathrm{OC}$, shorter operative time and reduced total time of hospitalization.
\end{abstract}

\section{Introduction}

At the beginning of LC it was introduced for cholecystitis as it provides the advantages of decrease pain and disability as well as improved cosmoses. However the role of LC in the settings of $\mathrm{AC}$ has been a subject of some debate. Earlier, AC was considered a contra indication to LC. $^{(1,}$ 2,3). Many clinics felt that the inflame mation, edema and adhesions associated this process made laparoscopic surgery unsafe. As more experience was gained in the field of laparoscopy in general, many patients with AC have been succ $\underset{(4.5 .6 .7)}{\text { essfully managed using LC technique }}$

The failure rate of $\mathrm{LC}$ for $\mathrm{AC}$ and conversion to $\mathrm{OC}$ in the deferent literatures varies markedly from $7 \%$ up to $30 \%$.
Studies attempting to identify risk factors contribute to conversion, have largely analyzed variables such as patient characteristics and radiographic findings. Although these studies may identify patient who have more technically challenging cholecystecto mies, they offer little in the way of improving outcome in any given patient after presentation. And in a trial to improve the success rate of LC for treatment of $\mathrm{AC}$, they ignore the patient variables as it is not under there control. But as they said, we can modify variables under our control, for example an operating surgeons experience with LC for AC, time from emergency admission to $\mathrm{LC}$, and equipment avail ability and familiality have been retrospectively identified as variables 
that may affect conversion rates from LC to OC in patients with AC. ${ }^{(9.10 .11)}$.

Aim of the work: is to evaluate laparoscopic cholecystectomy, is it safe, effective, and has a place in treat ment of acute cholecystilis. What is the rate of conversion to open cholec ystectomy and the important variables affect this conversion specially early presentation after the attack?

Material and methods: Between Jan.1997, and Dec. 1999 we conducted a study of 34 patients with $\mathrm{AC}$ underwent LC. The diagnosis of AC was established in patients who presented with upper right quadrant or epigastria acute pain of more than two hours duration, had upper right quadrant tenderness and localized peritoneal signs, and had a confirmatory sonogr amphic radiological study demonstra ting gall stones and evidence of $\mathrm{AC}$ such as gall bladder wall thickening, pericholecystic fluid or oedema, and ultrasound induced Murphy's sign. Also the diagnosis was confirmed by intraoperative findings. All patients with simple biliary colic, choledocholithiasis, billiary pancreatitis, or acalculus cholecystitis were excluded. The patients were devided into two groups based on the duration of acute symptoms to surgical intervention. "Early"intervention was defined as cholecystectomy performed within 72 hours from the onset of symptoms and "Delayed" intervention as surgery after $72 \mathrm{~h}$ up to 7 days from the onset of symptoms. Informations regarding the age, sex, duration of symptorns, previous operations or other biliary proplems were recorded. Routine investigations done to all patients, liver and kidney functions, CBC, electrolytes abdominal US and sometimes CT scan were done. Outcome variables including time from admission to operating room, operative time, post operative length of stay and total hospital stay were recorded and analyzed. Documentation of type of cholecystectomy LC or converted to OC were also recorded. Lastly all procedures were done in the presence of proper facilities. Lastly all procedures were done in presence of proper facilities such as well trained surgical and anaesthetic staff as well as appropriate equipment.

\section{Results}

Thirty four patients diagnosed as acute cholecystitis during the period from Jan 1997 to the end of 1999 were submitted for LC. Twelve patients of them underwent definitive procedure within $72 \mathrm{~h}$ from the onset of their acute symptoms "early group" and 22 patients underwent LC more than $72 \mathrm{~h}$ up to 7 days "delayed group" the average age was 43 years in the early treated group and 46 years in the delayed group. Two patients $(16.7 \%)$ of the early group had undergone pervious abdominal surgery as had 6 patients $(27 \%)$ of the delayed group. Six patents $(50 \%)$ of the early group and 15 patients $(68 \%)$ of delayed group had experien ced previous biliary symptoms. There was no significant difference in fever or leukocytosis between both groups at the time of presentation. The average duration of symptoms was $42 \mathrm{~h}$ for early group and more than 5 days for the delayed group table (1) .

The average operative time for the early intervention patients was 76 minutes and $93 \mathrm{~m}$. for delayed group. All procedures in early group were completed laparoscopically except one case $(8.3 \%)$, whereas 9 patients $(41 \%)$ of the delayed group required conver sion to open technique. The postop erative hospital stay and total hospital stay were shorter in the early group (1.3 and 2.2 days) compared with the delayed group ( 3 and 4.5 days). There 


\section{Ahmed M. Abozied, et al}

was only one case of complication among early group in which bile leakage occured and jaundice, and it is proved that it was due to miessed stone in the CBD, causing its obstruction and rupture of the cystic duct stump. The condition was managed by sphencterotomy and extraction of the stone through ERCP. There were two cases of wound infection in the delayed group of patients table (2) . Even when excluding patients who had conversion to OC, the operative time, postoperative stay and total hospital stay were still significantly lower in the early when compared with the delayed group .

Table (1) :- Prehospitalization data of patients.

\begin{tabular}{|l|l|l|}
\hline & Early group $\mathrm{n}=12$ & Delayed group $\mathrm{n}=22$ \\
\hline Mean age & 43 years & 46 years \\
\hline History of Biliary symptoms & 6 cases $=50 \%$ & 15 cases $=68 \%$ \\
\hline Previous abdominal operation & 2 cases $=16.7 \%$ & 6 cases $=27 \%$ \\
\hline Duration of acute symptoms & 42 hours & More than 5 days \\
\hline
\end{tabular}

Table (2):- Hospital data of patients (Excluding converted patients.

\begin{tabular}{|l|l|l|}
\hline & $\begin{array}{l}\text { Early group } \\
\mathrm{n}=12<72 \mathrm{~h}\end{array}$ & $\begin{array}{l}\text { Delayed group } \mathrm{n}=22 \\
>72 \mathrm{~h}\end{array}$ \\
\hline Operative time & 76 minutes & 93 minutes \\
\hline Conversion rate & One case $=8.3 \%$ & 9 cases $=41 \%$ \\
\hline Postoperative stay & 1.3 days & 3 days. \\
\hline Total hospitalization & 2.2 days & 4.5 days. \\
\hline $\begin{array}{l}\text { Complications:- } \\
\text { missed stone } \\
\text { infection }\end{array}$ & One case & ---- \\
\hline
\end{tabular}

Values expressed as median (range)

\section{Discussion}

In patients with $\mathrm{AC}$, should one operate by open surgery or late them "cool off" and delay them for 8 weeks? The answer from several trials is clear: Get it while it's hot. Laparoscopic cholecystectomy is more likely to be successful and complication free if it is performed within 72 hours of presentation. Not surprisingly, similar findings guided surgeons towards early surgery for AC before the laparoscopic era. ${ }^{(6)}$.

A "tough" gall bladder is a "tough" gall bladder whether one uses a kocher's incision or uses 4 trocars and titanium clips. The acute inflammation associated with AC creat an oedematus plane in the submucosa of the gall bladder (GB) which facilitates its dissection from the liver bed. The oedema may spread into triangle of Calot or it may stop at the fundus of gall bladder, leaving Calot's triangle reasonably free of inflammation. When acute inflammation mature to chronic one, neovascularity, fibrosis and contraction make LC substantially, more difficult and potentially more hazardous. The technical difficulty of LC is related to the operative finding. During early surgery, a distended, edematous gall bladder containing infected bile is frequently encountered, but this can be overcome by 
modifications in operative technique such as, use of $5^{\text {th }}$ cannula, GB decompression, use of sutures to control cystic duct, use of endoscopic pouches to retrieve specimen, or enlargement of umbilical incision ${ }^{(12)}$. Despite a longer operative time; the surgeon can often complete the cholecystectomy safely under the laparoscope. On the other hand, the chronicity of the GB disease may be more important than the acute inflammatory reaction in determining conversion to $\mathrm{OC}^{(13)}$. A number of risk factors for conversion with $\mathrm{AC}$, such as old age ${ }^{(13,14)}$, large stones ${ }^{(13)}$, history of previous biliary diseases, and non palpable $\mathrm{GB}^{(14)}$, are associated with repeated inflammation, which result in a scared and fibrosed GB. It is the presence of dense fibrotic adhesionsmore common in the delayed surgerythat render laparoscopic dissection impossible, and sometimes unsafe. Thus an initial conservative approach followed by interval elective operation cannot reduce the conversion rate and this holds true even for patients with acute symptoms for $72 \mathrm{~h}$ or more before $\operatorname{admission}^{(12)}$.

Hunter in $1998,{ }^{(9)}$ reported that , as a general rule, with patients who have acute cholecystitis, perform LC as soon as convenient within the first $72 \mathrm{~h}$. There is no benefit to attempting to "cool off" the GB before proceeding to the operating room. Laparasope or no laparoscope the message remains the same, for AC "get it while it's hot".

On the other hand, the delay from admission to surgery is surgeon-driven and is the key element of interest with regard to the optimal timing of surgery. If the operation is to be performed during the acute phase, it should be as soon after admission as possible ${ }^{(15)}$.

Greenwold and others in $2000,{ }^{(8)}$ in a trial to seek ways to improve LC outcome for $\mathrm{AC}$, they stressed that : safty of LC for AC is for the most part related to the surgeon's technical competency and sound clinical judg ment to convert to an open procedure should adequate, exposure not be obtained through the laparoscopic technique. They initiate a protocol for treatment of AC which is(when, where, and who) will treat the patient, to determinate outcome of the procedure. The "when" is as soon as possible after admission. The "where" is at specially equipped laparoscopic surgery unit. And the "who" is the house staff supervised by surgeons with special interest in therapeutic laparoscopy ${ }^{(8)}$.

Findings of several publications concentrating on some points compare ing early versus late $\mathrm{LC}$ for $\mathrm{AC}$ as well as our findings are summarized in table (3).

From these studies we feel that operation should be performed as early after onset of symptoms as possible. Also delaying surgical intervention for 6 to 8 weeks adds nothing except more hospital stay, and the risk of recurrence of other biliary complications ${ }^{(16)}$.

The rate of conversion from $\mathrm{LC}$ to $\mathrm{OC}$ in $\mathrm{AC}$ in some different studies as well as our results are show in table (4). 


\section{Ahmed M. Abozied, et al}

Table (3):- shows comparison of conversion rate in some different publications and our study.

\begin{tabular}{|l|l|l|}
\hline Auther & n & Important findings \\
\hline Chandler et al.(17) & 43 & $\begin{array}{l}\text { Early versus late (up to 5D after admission) was associated } \\
\text { with reduced operative time, lower conversion rate, lower } \\
\text { blood loss, lower hospital stay and charge. No differed in } \\
\text { complication, }\end{array}$ \\
\hline Lai et al.(18) & 104 & $\begin{array}{l}\text { No difference in conversion rate, Postoperative analgesics, or } \\
\text { complication. Early group had longer operative time and } \\
\text { shorter hospital stay }\end{array}$ \\
\hline Brodsky et al(6) & 215 & $\begin{array}{l}\text { The only controllable factor related to conversion rate was } \\
\text { duration of disease. Earlier operation was associated with } \\
\text { lower conversion rate. }\end{array}$ \\
\hline Eldar et al (7) & 130 & $\begin{array}{l}\text { Early (<96h) surgery had a conversion rate of 23\%. Late } \\
(>96 h) \text { had 47\% }\end{array}$ \\
\hline Willsher et al. (18) & 152 & $\begin{array}{l}\text { Conversion less likely in patents having surgery within 2 days } \\
\text { of admission. }\end{array}$ \\
\hline Lo et al. (19) & 99 & $\begin{array}{l}\text { Early operation (<72h from admission) was associated with a } \\
\text { lower conversion rate and complication rate. }\end{array}$ \\
\hline Our study & 34 & $\begin{array}{l}\text { Early intervention (<72h) was associated with a lower } \\
\text { conversion rate, lower hospital stay. }\end{array}$ \\
\hline
\end{tabular}

Table (4) shows the results of conversion rate in early and delayed groups of patients in the different literatures and our study.

\begin{tabular}{|l|l|l|l||}
\hline Auther & n & Early group & Delayed group \\
\hline Greenwald et al ${ }^{(8)}$ & 88 & $8 \%$ & $74 \%$ \\
\hline Eldar et al, ${ }^{(7)}$ & 130 & $23 \%$ & $47 \%$ \\
\hline Eldar et al, ${ }^{(19)}$ & 348 & 1435 & $39 \%$ \\
\hline LO et al ${ }^{(12)}$ & 99 & $11 \%$ & $23 \%$ \\
\hline Lujan et al, ${ }^{(20)}$ & 114 & $15 \%$ as a general conversion rate comparing LC and OC \\
\hline Our study & 34 & $8.3 \%$ & $41 \%$ \\
\hline
\end{tabular}

$\mathrm{n}=$ number of patients

Summery:- despite the well accepted success of LC in the elective treatment of symptomatic cholelithiasis, the efficacy and timing of this technique has been subject to some debate in the setting of AC. This study was undertaken to evaluate early LC as a safe, effective procedure for $\mathrm{AC}$ and the important variables that may play a major role in success rate of complition of LC.

In this study34 patients with $\mathrm{AC}$ were divided into two groups according to the duration of patient's symptoms before presentation ( $<72$ hours) 12 patients and $(>72 \mathrm{~h}) 22$ patients.
1.The operative time was 76 minutes for early patients and $93 \mathrm{~min}$ for delayed patients.

2.The conversion rate was $8.3 \%$ in early group and $41 \%$ in delayed group.

3.The postoperative and total length of hospital stay was 1.2 and 2.2 days for early group and 3.0 and 4.5 days for delayed group.

4.There is no difference in the complication rate between both groups.

Conclusion :-LC is a save and effective technique for treatment of AC. It has definite socioeconomic benefits. 
For surgeons, the optimal timing of $\mathrm{LC}$ for treatment of $\mathrm{AC}$ is as soon after onset of symptoms as possible.

Patients treated within $72 \mathrm{~h}$ of onset of symptoms, experience a lower conversion rate to $\mathrm{OC}$, shorter operative time and reduce the postoperative stay, reduce the total hospital stay.

\section{References}

1. Gadacz TR, Talamini MA, Lillemoe KD, Yeo CJ. Laparoscopic cholecyste ctomy. Surg clin North Am 1990;70:1249-62

2. Cuschieri A, Berci G, McSherry CK. Laparoscopic cholecystectomy. Am J Surj 1990;159:273

3. Phillips EH, Caroll BJ, Fallas MJ. Laparoscopically guided cholecystec tomy: a detailed report of the first 453 cases performed by one surgical team. Am surg 1993; 59:235-42.

4. Pessaux P, Tuech JJ, Rouge C, et al. Laparoscopic cholecystectomy in acute cholecystitis: a postoperative compara tive study in patients with acute versus chronic cholecystitis. Surg Endosc 2000; 14:358-61.

5. Zucker KA, Flowers JL, Bailey RW, et al. Laparoscopic management of acute cholecystitis. Am J Surg 1993; 165:508-14.

6. Brodsky A, Matter I, Sabo E, et al. Laparoscopic cholecystectomy for acute cholecystitis: can the need for convertion and the probability of complications be predicted? Surg endosc 2000; 14:755-60.

7. Eldar S, Sabo E,Nash E, et al. Laparoscopic cholecystectomy for acute cholecystitis: prospective trial. Warld J Surg 1997; 21:540-5.

8. Greenwald JA, McMullen HF, Coppa GF, Numan RM. Standerdization of surgeon-controlled varibles: impact on outcome in patients with acute chole cystitis. Ann Surg 2000; 231: 339-44.

9. Hunter JG. Acute cholecystitis revisited: get it while it's hot. Ann surg 1998; 227 (4): 468-469.
10. Wiebke EA, Pruitt AL, Howard TJ, et al. Conversion of laparoscopic to open cholecystectomy. An analysis of risk factors. Surg Endosc 1996; 10(7): 742745

11. Bickel A, Rappapot A, Kanievski V, et al. Laparoscopic management of acute cholecystitis. Prognstic factors for success. Surg Endosc 1996; 10(11): 1045-1049.

12. Lo CM, Liu CL, Fan ST, et al. Prospective randomised study of early versus delayed laparoscopic cholecyste -ctomy for acute cholecystitis. Ann surg 1998; 227: 461-7.

13. Lo CM, Fan ST, Liu CL, et al. Early decision for conversion of laparoscopic to open cholecystectomy for treatment of acute cholecystitis. Am J Surg 1997; 173: 513-517.

14. Eldar S, Sabo E, Nash E, et al. Laparo scopic cholecystectomy for acute cholecystitis: prospective trial. World J Surg 1997; 21: 540-545.

15. Rattner DW, Ferguson C, Warshaw AL. Factors associated with successful laparoscopic cholecystectomy for acute cholecystitis. Ann Surg 1993; 217: 233236.

16. Lai PBS, Kwong $\mathrm{KH}$, et al. Randomised trial of early versus delayed laparoscopic cholecystectomy for acute cholecystitis. Br J Surg 1998; 85: 764-7.

17. Chandler CF, Lane JS, Ferguson P, et al. 2000; 66:896-900.

18. Willsher PC, Sanabria JR, Gallinger S, et al. Early laparoscopic cholecyst ectomy for acute cholecystitis:a safe prosedure. Gastrointest Surg 1999; 3: 50-53.

19. Eldar S, eilan A, Bickel A, et al. The impact of patient delay and physicion delay on the outcome of laparoscopic cholecystectomy for acute cholecystitis. Am J Surg. 1999; 178: 303-307.

20. Lujan JA, Parrilla P, Robles R, et al. laparoscopic cholecystectomy versus open cholecystectomy in treatment of acute cholecystitis. Arch Surg 1998; 133: 173-175. 


\section{Ahmed M. Abozied, et al}

التغيرات التى تؤثر على نتائج استخدام منظار البطن لاستئصال المرارة

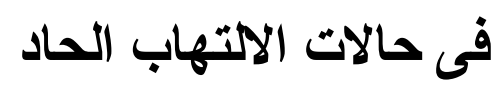

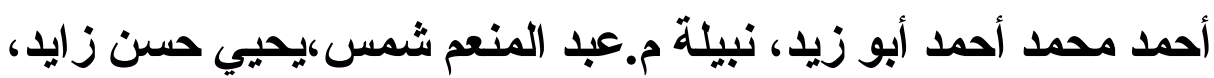

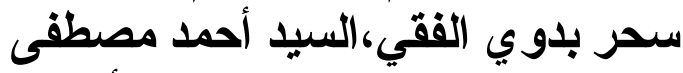

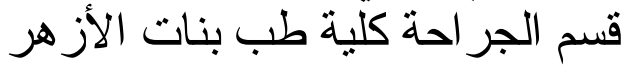

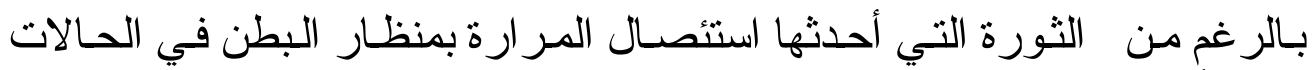

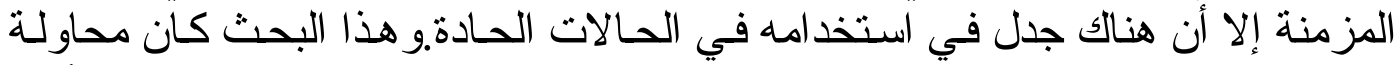

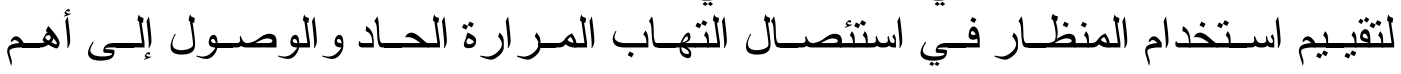

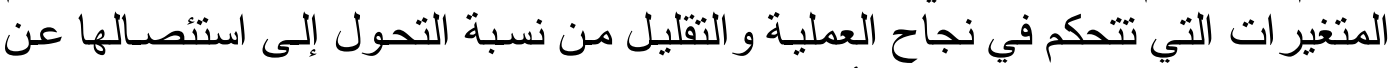

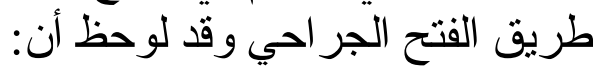

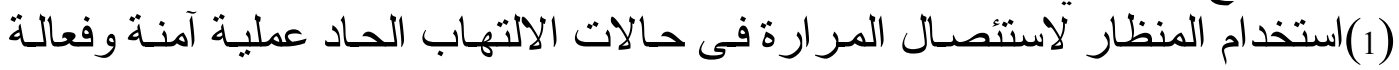
وله فو ائد اقتصادية كبيرة. (2) أنسب توقيت لأجر اء العملية هو مبكر ا بعد حدوث أعر اض الالتهاب الحاد وذلك كلما أمكن.

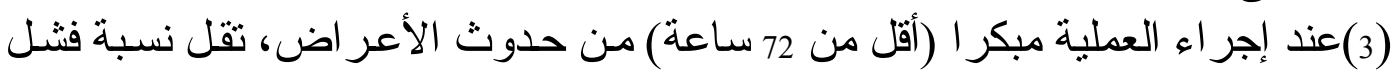

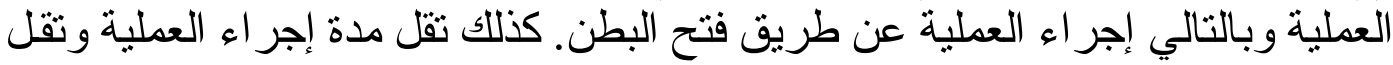

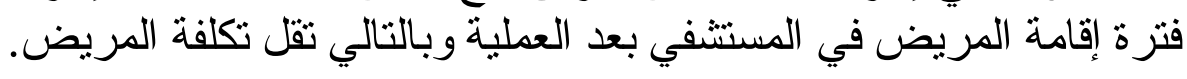

